\title{
Certified Clinical Research Coordinator
}

National Cancer Institute

\section{Source}

National Cancer Institute. Certified Clinical Research Coordinator. NCI Thesaurus. Code C71297.

A clinical research coordinator or study coordinator with related work experience and with certification earned by passing a required program and written examination from the Association of Clinical Research Professionals (ACRP) or equivalent organization. 